\title{
IMOBILIZAÇÃO DE PEROXIDASE DE RAIZ FORTE EM BAGAÇO DE CANA-DE-AÇÚCAR
}

\author{
Monna Lisa B. Queiroz ${ }^{\mathrm{a}, \mathrm{b}}$, Kennedy C. da Conceição ${ }^{\mathrm{a}, \mathrm{b}}$, Micael Nunes Meloa,b, Osmar Calderón Sánchez ${ }^{\mathrm{a}}$, Heiddy M. \\ Alvarez $^{\mathrm{d}}$, Cleide M. F. Soares ${ }^{\mathrm{a}, \mathrm{b}}$ e Alini T. Fricks ${ }^{\mathrm{a}, \mathrm{b}, *}$ \\ aLaboratório de Engenharia de Bioprocessos, Instituto de Tecnologia e Pesquisa, Av. Murilo Dantas, 300, $49032-490$ Aracaju - \\ SE, Brasil \\ bUniversidade Tiradentes, Av. Murilo Dantas, 300, 49032-490 Aracaju - SE, Brasil \\ 'Laboratorio de Síntesis Orgánica, Facultad de Química, Universidad de La Habana, 10400, La Habana, Cuba \\ ${ }^{\mathrm{d}}$ Departamento de Ciências Exatas, Universidade Estadual de Feira de Santana, km 03 BR 116, 44031-460 Feira de Santana - BA, \\ Brasil
}

Recebido em 10/05/2018; aceito em 25/07/2018; publicado na web em 22/08/2018

\begin{abstract}
IMMOBILIZATION OF HORSERADISH PEROXIDASE ON SUGARCANE BAGASSE. The immobilization of horseradish peroxidase (HRP) on raw and alkaline pre-treated sugarcane bagasse by physical adsorption (ADS) and covalent bond (LC) methods was studied. The saturation of the support with $2 \mathrm{mg}$ of HRP/g of support by LC immobilization reached 35\% of immobilization efficiency and 39 units of the immobilized enzyme (U). Regarding the HRP immobilization on sugarcane bagasse without pretreatment and using the same HRP loading, it was observed a reduction in the efficiency of immobilization and in the number of immobilized units for both methods, ADS (13.98\% and $15.46 \mathrm{U})$ and LC (15.79\% and $17.46 \mathrm{U})$. The sugarcane bagasse with alkaline pretreatment experiment, on the other hand, exhibited higher potential for HRP immobilization by LC. The supports and biocatalysts were characterized by Fourier transform infrared spectroscopy (FTIR), showing greater availability of hydroxyl groups in the pretreated support and the typical amide I and amide II bands that corroborate the effectiveness of the enzyme immobilization on sugarcane bagasse. In the same way, the thermogravimetric analysis (TGA) confirmed a higher weight loss in the region I for the derivative immobilized by LC, suggesting the presence of water favored enzymatic activity.
\end{abstract}

Keywords: sugarcane bagasse; immobilization; horseradish peroxidase.

\section{INTRODUÇÃO}

No Brasil a produção de cana-de-açúcar é tradicional e vem aumentando continuamente, atingindo aproximadamente 768.678.382 milhões de toneladas em 2016, o que representa 40,7\% de produção mundial. ${ }^{1,2}$ Esse volume produzido gera aproximadamente 2,5 mil toneladas por dia de bagaço da cana, ${ }^{3}$ portanto, estudos que focam na utilização dos resíduos agroindustrial em diferentes aplicações promovem uma redução de custos de produção e obtém novos compostos de valor agregado para o setor industrial. ${ }^{4}$ Neste sentido destacam-se as rotas biotecnológicas para utilização destes resíduos, ${ }^{5}$ como por exemplo, a utilização para a produção de bioetanol ( $2^{\mathrm{a}}$ geração $)^{6,7}$ e a utilização de resíduos agroindustriais como suporte para imobilização de enzimas. ${ }^{8} \mathrm{O}$ bagaço de cana-de-açúcar apresenta na sua composição celulose $(38,3 \%)$, hemicelulose $(20,1 \%)$ e lignina $(29,0 \%)^{9}$ o que torna este tipo de suporte atrativo para imobilização de enzimas em virtude da vasta possibilidade de pontos reativos. Tais alternativas, portanto, apresentam grande relevância do ponto de vista ambiental e econômico, pois propicia a reutilização destes resíduos e a geração de produtos de alto valor agregado. ${ }^{10}$

Os estudos avaliando a imobilização de horseradish peroxidase (HRP) em resíduo lignocelulósico indicam o potencial do uso de biomassa de diferentes origens, como por exemplo, a fibra de lã. ${ }^{11} \mathrm{Na}$ maioria dos suportes de material lignocelulósico faz-se necessário seu pré-tratamento com o objetivo de quebrar/desestruturar a lignina e hemicelulose, permitindo uma melhor acessibilidade a celulose. ${ }^{12-14}$ Dentre os diversos métodos de pré-tratamentos destaca-se o método alcalino, no qual são aplicadas condições menos severas quando comparadas a outros métodos como, por exemplo, os pré-tratamentos ácidos. ${ }^{13,14}$
A literatura relata com sucesso a imobilização de enzimas em material lignocelulósico, ${ }^{8,10,15}$ entretanto ainda não foi verificada a utilização de bagaço de cana-de-açúcar para a imobilização de peroxidases. Dentre as oxidorredutases, as peroxidases vegetais constituem enzimas de interesse para imobilização devido à versatilidade em oxidar diversas substâncias, tornando-as aplicáveis tanto do ponto de vista ambiental, para controle e monitoramento de poluentes, como do ponto de vista sintético com a transferência seletiva de oxigênio. ${ }^{11}$ A peroxidase de raiz forte ou horseradish peroxidase (HRP) é a peroxidase vegetal das oxidorredutases e apresenta diversificadas aplicações, tais como: a remoção de fenóis de efluentes, descoloração de corantes sintéticos, desenvolvimento de biossensores, análises e kits de diagnósticos, imunoensaios enzimáticos e síntese orgânica. ${ }^{16,17}$

Deste modo, o objetivo deste trabalho foi avaliar a imobilização de HRP em bagaço de cana-de-açúcar previamente tratado pelo método alcalino e caracterizar os biocatalisadores imobilizados por FTIR e termogravimetria (TG).

\section{EXPERIMENTAL}

\section{Enzima e materiais}

Peroxidase de raiz forte, isoenzima C $(\mathrm{HRP})(\mathrm{RZ}=3.0)$ $\left(98,15 \pm 7,38 \mathrm{U} / \mathrm{mg}\right.$ - oxidação do guaiacol, $\left.\mathrm{pH} 6,0,25^{\circ} \mathrm{C}\right)$, glutaraldeído $2,5 \%(\mathrm{v} / \mathrm{v})$ e aminopropiltrietoxisilano (APTS) foram adquiridos da Sigma-Aldrich (Aldrich, Milwaukee, WI, USA). Fosfato de sódio $\left(\mathrm{Na}_{2} \mathrm{HPO}_{4} \cdot 2 \mathrm{H}_{2} \mathrm{O}\right)$, hidróxido de sódio $(\mathrm{NaOH})$, guaiacol e peróxido de hidrogênio $30 \%$ (solução aquosa) (Vetec Química, RJ, Brasil). 


\section{Pré-tratamento do suporte orgânico}

O suporte foi preparado conforme metodologia proposta por Santos et al. ${ }^{18}$ com pequenas modificações. O bagaço da cana-deaçúcar foi adquirido no mercado local, armazenado, transportado à temperatura ambiente e triturado em moinho de facas. Em seguida, o bagaço da cana-de-açúcar foi lavado com água destilada e seco a $100{ }^{\circ} \mathrm{C}$ até atingir massa constante. Para o tratamento alcalino, $5 \mathrm{~g}$ de bagaço seco foram transferidos para frascos Erlenmeyer contendo $250 \mathrm{~mL}$ de $\mathrm{NaOH}\left(0,5 \mathrm{~mol} \mathrm{~L}^{-1}\right)$ e mantidos sob agitação rotativa a 120 rpm durante 24 horas. Posteriormente, o bagaço da cana-deaçúcar foi lavado com água destilada até neutralização do $\mathrm{pH}$ e seco a $100{ }^{\circ} \mathrm{C}$ até a massa constante. Por fim, o tamanho das partículas do suporte orgânico foi reduzido em peneira padrão de 16 mesh.

\section{Imobilização da peroxidase}

Peroxidase de raiz forte foi imobilizada por adsorção física (ADS) e ligação covalente (LC) em bagaço de cana-de-açúcar pré-tratado e não tratado. Em todas as metodologias a imobilização foi conduzida em tampão fosfato $\left(\mathrm{Na}_{2} \mathrm{HPO}_{4} \cdot 2 \mathrm{H}_{2} \mathrm{O}\right) 100 \mathrm{mmol} \mathrm{L}{ }^{-1} \mathrm{pH} 8,0$, meio que propicia maior eficiência de imobilização conforme a literatura. ${ }^{19} \mathrm{O}$ efeito do carregamento de HRP na faixa de 0,125-2,5 mg de HRP/g de suporte foi avaliado. Na adsorção física foi utilizado $1 \mathrm{~g}$ de suporte previamente seco, que foram suspensos em tampão fosfato e mantidos sob agitação mecânica por 15 minutos. Em seguida, adicionou-se a solução de $\operatorname{HRP}(0,1 \mathrm{mg} / \mathrm{mL})$ preparada em tampão fosfato de sódio $100 \mathrm{mmol} \mathrm{L}^{-1} \mathrm{pH}$ 8,0 de forma a atender o carregamento de enzima desejado, e posteriormente adicionou-se tampão até o volume final de $10 \mathrm{~mL}$. O sistema foi mantido sob agitação por 3 horas a $25^{\circ} \mathrm{C}$, em seguida, armazenado a $4{ }^{\circ} \mathrm{C}$ em condição estática, durante 24 horas. Posteriormente, o biocatalisador imobilizado foi filtrado e lavado com tampão para retirada de enzimas não adsorvidas e o filtrado foi reservado para quantificação da atividade enzimática.

Para a metodologia de imobilização por ligação covalente inicialmente o suporte $(1 \mathrm{~g})$ foi silanizado com aminopropiltrietoxisilano (APTS) $0,5 \%(\mathrm{v} / \mathrm{v})$, em seguida foi ativado com 4,6 mL de uma solução de glutaraldeído 2,5\% (v/v). A mistura foi mantida em banho-maria por 1 hora a $25^{\circ} \mathrm{C}$, em seguida, foi filtrada a vácuo e lavada com 3 porções de $10 \mathrm{~mL}$ de água destilada. O procedimento utilizado para a imobilização por LC foi o mesmo adotado para a adsorção física. A determinação da umidade do biocatalisador imobilizado foi realizada por titulometria (Karl Fisher) em equipamento Metrohm.

\section{Determinação da atividade peroxidásica}

A atividade enzimática de peroxidase de raiz forte (HRP) foi determinada por método colorimétrico, baseado na mudança de absorvância a $470 \mathrm{~nm}$ devido à formação do produto de oxidação do guaiacol, o tetraguaiacol durante três minutos $\left(\varepsilon_{\text {tetraguaiacol }}: 26,6 \mathrm{mmol}^{-1} \mathrm{~L} \mathrm{~cm}^{-1}\right){ }^{20}$ O ensaio contém $2,76 \mathrm{~mL}$ de tampão fosfato de sódio $100 \mathrm{mmol} \mathrm{L}^{-1}$ (pH 6,0); 0,04 mL da solução enzimática diluída 200 vezes em tampão pH 6,0; 0,1 mL de solução de guaiacol $100 \mathrm{mmol} \mathrm{L}^{-1}$ e $0,1 \mathrm{~mL}$ de peróxido de hidrogênio $\left(\mathrm{H}_{2} \mathrm{O}_{2}\right) 2,0 \mathrm{mmol} \mathrm{L}{ }^{-1}$ a $25^{\circ} \mathrm{C}$. Uma unidade de enzima (U) foi definida como a quantidade de enzima capaz de fornecer $1 \mu$ mol de produto em 1 minuto a $25^{\circ} \mathrm{C} \mathrm{em} \mathrm{pH} \mathrm{6,0.}$

A eficiência de imobilização (\%) e o número de unidades de enzima imobilizada (U) foram determinados pela diferença entre número de unidades de atividade peroxidásica oferecidas $\left(U_{\mathrm{o}}\right)$ e o número de unidades de enzima remanescente no filtrado $\left(\mathrm{U}_{\mathrm{f}}\right)$, conforme Eq. $1 .{ }^{19}$

$$
\text { Eficiência de imobilização }(\%)=\frac{\left(U_{o}-U_{f}\right) 100}{U_{o}}
$$

\section{Caracterização físico-química do suporte e biocatalisador} imobilizado

As curvas termogravimétricas (TG) foram obtidas para o suporte de bagaço de cana-de-açúcar (BC) e para os biocatalisadores imobilizados (ADS e LC), utilizando o equipamento TG-IRIS Netzsch, sob atmosfera de nitrogênio, na faixa de $35-600{ }^{\circ} \mathrm{C} / 10{ }^{\circ} \mathrm{C} / \mathrm{min}^{-1}$ e sob atmosfera de ar sintético na faixa de $800-900{ }^{\circ} \mathrm{C} \mathrm{min}^{-1}$. O suporte e os biocatalisadores imobilizados foram submetidos à análise de Espectroscopia de Infravermelho com transformada de Fourier FTIR no intervalo de comprimento de onda de $400-4000 \mathrm{~cm}^{-1} \mathrm{em}$ equipamento FTIR BOMEMMB-100.

\section{RESULTADOS E DISCUSSÃO}

\section{Imobilização de HRP em bagaço de cana-de-açúcar}

O efeito do carregamento de HRP (0,125 - 2,5 mg de HRP/g de suporte) na imobilização de HRP em bagaço de cana-de-açúcar por adsorção física (ADS) e por ligação covalente (LC) em suporte ativado com glutaraldeído 2,5\% (v/v) é mostrado nas Figuras 1 e 2.

A Figura 1 mostra que no método de imobilização por adsorção física (ADS) a eficiência de imobilização foi constante, em torno de $30 \%$, com carregamento entre 0,125 e $2 \mathrm{mg}$ de $\mathrm{HRP} / \mathrm{g}$ suporte, e que em carregamento superior (2,5 mg de HRP/g suporte) ocorre uma diminuição na eficiência para 19\%. Utilizando-se outro método de imobilização, a ligação covalente (LC), verificou-se o aumento na eficiência de imobilização com o aumento no carregamento no intervalo de 0,125 a $2 \mathrm{mg}$ de $\mathrm{HRP} / \mathrm{g}$ de suporte (aumento de 22 para $35 \%$ na eficiência de imobilização). Os dados indicam que a ativação do suporte na imobilização por LC disponibiliza grupamentos reativos para a ligação da enzima ao suporte e por isso observa-se um perfil crescente na eficiência de imobilização com o aumento do carregamento de enzima. Ambas as metodologias de imobilização empregadas, ADS e LC, forneceram baixos números de unidades de enzima imobilizadas e eficiência de imobilização com menores carregamentos de enzima, o que pode ser atribuído ao efeito da concentração de enzima que, em baixa concentração, acarreta em menor número de unidades de enzima imobilizadas. Os resultados mostram que o carregamento de $2 \mathrm{mg}$ de HRP/g suporte é considerado ideal para imobilização de HRP por ADS e LC em bagaço de cana-de-açúcar pré-tratado (eficiência de imobilização: ADS - 31\% e LC - 35,3\%; número de unidades imobilizadas: ADS - 34 U e LC - 39 U) (Figuras 1 e 2). Na Figura 2 mostra que carregamento superior a $2 \mathrm{mg}$ de $\mathrm{HRP} / \mathrm{g}$ de suporte promove uma diminuição na eficiência de imobilização e no número de unidades imobilizadas. Este resultado é atribuído provavelmente à sobrecarga de enzima no suporte que leva à limitações difusionais para o substrato. ${ }^{11}$

A imobilização de HRP em bagaço de cana-de-açúcar sem tratamento alcalino (carregamento de $2 \mathrm{mg}$ de $\mathrm{HRP} / \mathrm{g}$ de suporte) forneceu eficiência de imobilização e número de unidades imobilizadas cerca de $50 \%$ inferior à obtida quando utilizou-se o bagaço de cana-de-açúcar pré-tratado em ambas metodologias de imobilização (ADS - 13,98\% e 15,4 U e por LC - 15,79\% e 17,4 U). Portanto, o resultado indica que o pré-tratamento alcalino possivelmente desorganiza as estruturas de hemicelulose e lignina, disponibilizando os grupamentos hidroxila presentes na estrutura do suporte..$^{13,14}$

Menores valores para o número de unidades imobilizadas e eficiência de imobilização na adsorção física, 34 U e $31 \%$ respectivamente, comparada à LC (39 U e 35,3\%) pode ser justificado pela presença de forças fracas de ligação entre o suporte e a enzima. Deste modo, o biocatalisador imobilizado por LC possui maior potencial de aplicação baseado nos dados de eficiência de imobilização e número de unidades imobilizadas. 


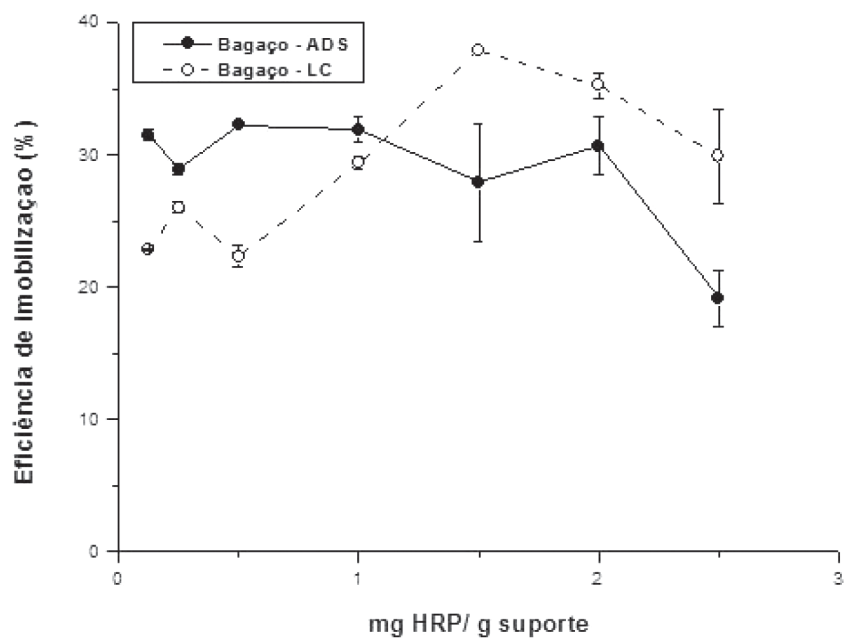

Figura 1. Eficiência de imobilização de HRP em bagaço de cana-de-açúcar por adsorção física $(A D S)$ e por ligação covalente $(L C)$

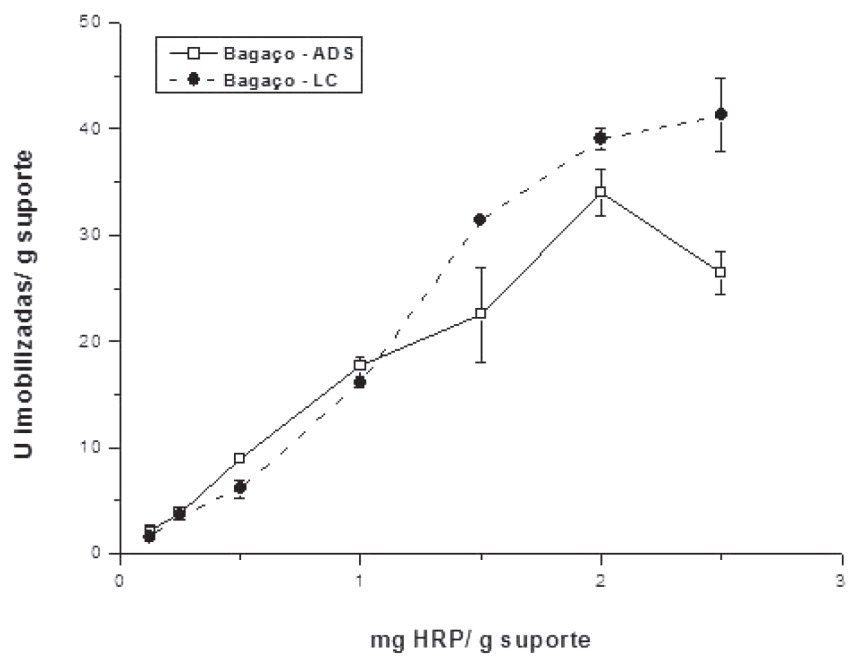

Figura 2. Efeito da variação do carregamento $(0,125-2,5 \mathrm{mg}$ de HRP/g de suporte) no número de unidades de HRP imobilizadas em bagaço de cana-de-açúcar por adsorção física (ADS) e ligação covalente $(L C)$

Poucos estudos relatam a imobilização de oxidase por ADS em material lignocelulósico. Lacase comercial foi imobilizada por ADS em fibra de coco verde utilizando carregamento de enzima inferior ao utilizado no presente trabalho $(0,67 \mathrm{mg}$ de enzima/g suporte). O biocatalisador foi imobilizado com eficiência de imobilização (38+9\%), similar à obtida no presente trabalho. A imobilização da lacase mostra a potencialidade de utilização de oxidases para os processos de imobilização em resíduos lignocelulósicos. ${ }^{21}$

No método de imobilização por ligação covalente os biocatalisadores são ligados covalentemente ao suporte e são geralmente mais estáveis e resistentes às mudanças das condições do ambiente (intervalo de $\mathrm{pH}$ e temperatura), características de grande interesse para a indústria. ${ }^{10} \mathrm{~A}$ literatura descreve a utilização de materiais lignocelulósicos ativados por grupos funcionais orgânicos que reagem com grupos hidroxila presentes na superfície, propiciando a ligação covalente da enzima a esse tipo de material. ${ }^{10}$ Desta forma, a utilização de grupos funcionais orgânicos, por exemplo, o aminopropiltrietoxisilano, seguido do uso de agentes funcionalizantes, possibilitam uma forte interação por ligação covalente entre a enzima e o suporte. ${ }^{22}$

Métodos de imobilização de HRP em bagaço de cana-de-açúcar até o momento não foram descritos na literatura. No presente estudo a eficiência de imobilização máxima foi de cerca de $35 \%$, na LC, o que equivale a aproximadamente $0,7 \mathrm{mg}$ de enzima imobilizada/g suporte. A literatura relata a imobilização de peroxidase de raiz forte, pré-purificada por precipitação com sulfato de amônio, por ligação covalente em resíduo de fibra de lã ativada com cloreto cianúrico na concentração de $2 \% .{ }^{11}$ Foram recuperados $72 \%$ da atividade oferecida com carregamento de aproximadamente $0,1 \mathrm{mg}$ de enzima/g de suporte, ou seja, o biocatalisador imobilizado continha $0,07 \mathrm{mg}$ de proteína imobilizada/g de suporte, um resultado 10 vezes inferior ao obtido neste trabalho, salientando que no estudo foi utilizada enzima não totalmente purificada. $\mathrm{O}$ menor valor para eficiência de imobilização pode estar associado à natureza do suporte, que ao contrário da fibra de lã que é composta por celulose e proteína, o bagaço de cana-de-açúcar apresenta além de lignina, majoritariamente a celulose, estrutura complexa em que a disponibilização dos grupamentos reativos hidroxilas é dificultada, diminuindo a possibilidade de interação dos grupamentos hidroxilas do suporte ao agente bifuncional glutaraldeído e por fim aos grupos amino da enzima. Segundo Aditiya et al. ${ }^{6}$ o pré-tratamento alcalino submetido em material lignocelulósico promove a degradação da lignina, resultando na exposição dos grupamentos hidroxila presentes na estrutura da celulose possibilitando a interação entre a enzima e o suporte nos diferentes métodos de imobilização. ${ }^{10}$

\section{Caracterização físico-química do suporte de bagaço de cana- de-açúcar e dos biocatalisadores imobilizados}

A utilização da caracterização físico-química confirma a imobilização selecionada neste estudo. A análise de Espectroscopia de Infravermelho com Transformada de Fourier (FTIR) indica a presença de bandas de absorção características de grupos funcionais presentes na enzima livre, no suporte e nos biocatalisadores imobilizados. A partir da comparação destes espectros de FTIR pode-se confirmar a presença da proteína no suporte. ${ }^{23}$ Os espectros de FTIR referentes ao suporte com prévio tratamento alcalino (BC), o suporte sem tratamento alcalino (BCS), à enzima (HRP livre) e aos biocatalisadores imobilizados (ADS e LC) são mostrados na Figura 3. Em todos os espectros observa-se banda característica de vibração referente à hidroxila (O-H). Para $\mathrm{BC}$ a banda em $3400 \mathrm{~cm}^{-1}$ é atribuída às vibrações das hidroxilas presentes no suporte. ${ }^{24}$ Além disso, para os suportes e biocatalisadores imobilizados (ADS e LC) esta banda está associada às vibrações das hidroxilas $(\mathrm{O}-\mathrm{H})$ provenientes da umidade residual do bagaço e também à água estrutural da proteína, que possivelmente se liga aos grupamentos hidroxila do suporte por meio de ligações de hidrogênio. ${ }^{24}$

O espectro de $\mathrm{BC}$ mostra banda em $1640 \mathrm{~cm}^{-1}$ referente à vibração $\mathrm{C}=\mathrm{C}$ dos anéis aromáticos ${ }^{25}$ Nos derivados imobilizados observa-se o deslocamento da banda para a região de $1650 \mathrm{~cm}^{-1}$, o que indica a presença da enzima em ADS e LC. O espectro de FTIR da HRP livre apresenta bandas intensas em $1658 \mathrm{~cm}^{-1}$ (amida I) e $1536 \mathrm{~cm}^{-1}$ (amida II), características da ligação peptídica da enzima (estiramento $\mathrm{C}-\mathrm{O}$ da carbonila, deformação N-H e vibração C-N da amida). ${ }^{11,26,27}$ Estas bandas aparecem também nos derivados imobilizados. Nos espectros de BC, BCS e biocatalisadores imobilizados a banda de absorção em $897 \mathrm{~cm}^{-1} e$ é atribuída ao alongamento (C-O-C) característico de ligações glicosídicas entre as unidades de açúcar presentes na estrutura da celulose.$^{28}$ Esta banda não aparece no espectro da enzima livre. Além disso, os espectros de BC, BCS e biocatalisadores imobilizados (ADS e LC) apresentaram bandas entre 1030-1064 cm'-1 também características da celulose..$^{29}$ Observaram-se bandas de absorção entre 1100 e $1300 \mathrm{~cm}^{-1}$ de vibrações em grupos fenólicos (C-O-H). Bandas características nos espectros de BC, BCS e biocatalisadores imobilizados foram atribuídos às vibrações de anéis (C-O-C) de hemicelulose $\left(1165 \mathrm{~cm}^{-1}\right)$ e bandas em $1375 \mathrm{~cm}^{-1}$ de grupos metil $\left.\left(\mathrm{CH}_{3}\right)\right)^{24,30}$ 


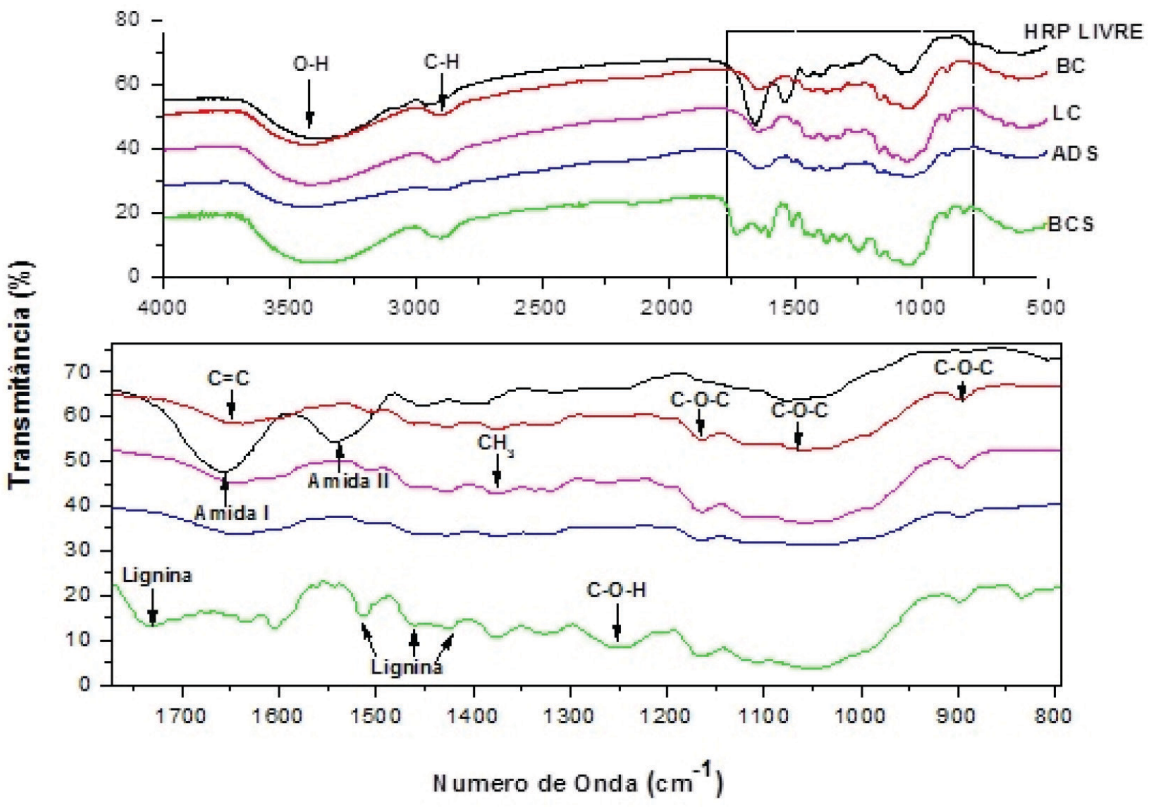

Figura 3. Espectro de FTIR: HRP livre, bagaço de cana-de-açúcar (BC), bagaço de cana-de-açúcar sem tratamento alcalino (BCS), biocatalisadores imobilizados por adsorção física (ADS) e ligação covalente $(L C)$

Observaram-se nos espectros dos suportes BC, BCS e biocatalisadores imobilizados banda de absorção em $2908 \mathrm{~cm}^{-1}$ que está associada a deformação axial de grupos $\mathrm{C}-\mathrm{H}$ presente no bagaço de cana-de-açúcar. Além disso, o suporte BCS apresentou maior intensidade das bandas sugerindo que a estrutura do material foi alterada com o tratamento alcalino. ${ }^{30}$ No espectro do suporte sem tratamento alcalino (BCS) observam-se bandas mais intensas que são características da lignina $\left(1426,1462 \text { e } 1511 \mathrm{~cm}^{-1}\right)^{29}$ quando comparados ao suporte $\mathrm{BC}$ e biocatalisadores imobilizados, confirmando que o tratamento alcalino foi eficiente para a desestruturação da lignina presente no material lignocelulósico e permitiu uma maior disponibilidade de hidroxilas reativas no suporte. A análise de FTIR possibilitou a confirmação da eficiência de imobilização de HRP em bagaço de cana-de-açúcar com tratamento alcalino, utilizando os métodos por ADS e LC, além da presença de bandas características do suporte e da enzima permite propor os mecanismos de imobilização de HRP em bagaço de cana-de-açúcar por ADS e LC.

A adsorção física baseia-se na bioafinidade enzima-suporte e constitui uma das metodologias mais utilizadas na obtenção de biocatalisadores insolúveis. ${ }^{21} \mathrm{~A}$ imobilização de HRP em bagaço de cana-de-açúcar (material lignocelulósico) por ADS é proposta na Figura 4. Na imobilização por adsorção a enzima interage com o suporte por meio de interações intermoleculares fracas. Os grupamentos hidroxila dos anéis piranosídicos do suporte podem interagir por meio de ligações de hidrogênio com grupamentos carboxilatos livres da enzima conforme sugerido na Figura $4 .^{31}$

A imobilização de HRP por ligação covalente é proposta na Figura 5. Inicialmente o suporte é silanizado com o agente aminopropiltrietoxisilano (APTS) (Figura 5A), seguido da ativação com o glutaraldeído (2,5\%) (Figura 5B). O grupamento aldeído do glutaraldeído liga-se covalentemente ao suporte e posteriormente o grupo amino da enzima ataca nucleofilicamente a carbonila do suporte ativado, possibilitando ligação estável entre a enzima e o suporte (Figura $5 \mathrm{C}$ ). ${ }^{32-34}$

A termogravimetria (TG) é utilizada para caracterizar materiais por meio de alterações das propriedades físicas e químicas como a mudança de fase, a desidratação e decomposição do material em função do aumento da temperatura. Para biocatalisadores imobilizados é observada a degradação da proteína e do suporte com o aumento da temperatura,

\section{ADSORÇÃO FÍSICA}

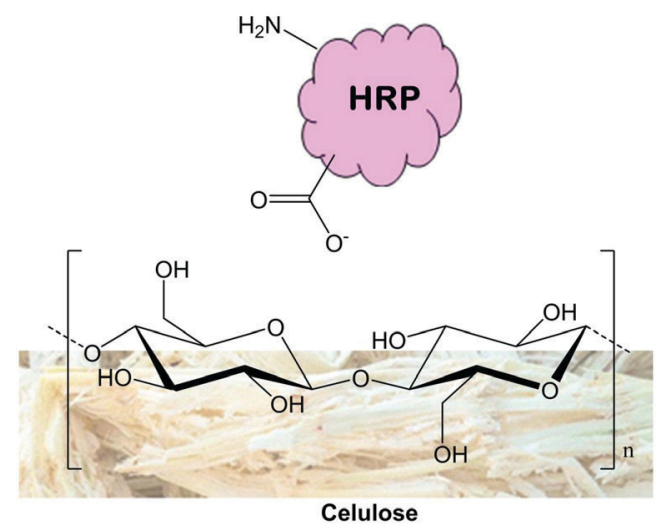

Figura 4. Proposta de imobilização de HRP em bagaço de cana-de-açúcar por adsorção física (ADS)

por meio da perda de massa com a evaporação destes componentes. ${ }^{23}$ A fim de complementar os resultados referentes à imobilização, foi realizada análise termogravimétrica. As perdas de massa em função da temperatura foram verificadas por TG para HRP livre, bagaço de cana-de-açúcar (BC) e para os biocatalisadores imobilizados por ADS e LC (Tabela 1). Constata-se que a perda de massa na região I é possivelmente atribuída à água, que para HRP livre $(9,5 \%)$ foi maior comparada ao biocatalisador imobilizado por $\operatorname{LC}(8,5 \%), \operatorname{ADS}(7,9 \%)$ e BC $(6,9 \%)$. Verificou-se maior perda de massa para o biocatalisador imobilizado por LC comparado à $\mathrm{ADS}$ o que indica que a presença de água favoreceu a atividade catalítica de HRP. Portanto, a imobilização de HRP por LC pode estar associada à maior conservação da camada de hidratação da enzima que é reconhecidamente relacionada à manutenção da atividade catalítica da enzima. ${ }^{35,36}$

A Figura 6 mostra um termograma típico referente ao biocatalisador imobilizado por LC. Em todos os termogramas referentes ao suporte (bagaço de cana-de-açúcar pré-tratado) e aos biocatalisadores imobilizados, observou-se na região I $\left(25-200{ }^{\circ} \mathrm{C}\right)$ perda de massa referente à desidratação. A região II $\left(200-600{ }^{\circ} \mathrm{C}\right)$ está vinculada à decomposição de compostos orgânicos $(\mathrm{C}, \mathrm{H}, \mathrm{O} \text { e N })^{35}$ que incluem HRP livre, $\mathrm{BC}$ e os biocatalisadores imobilizados. Nessa região as 


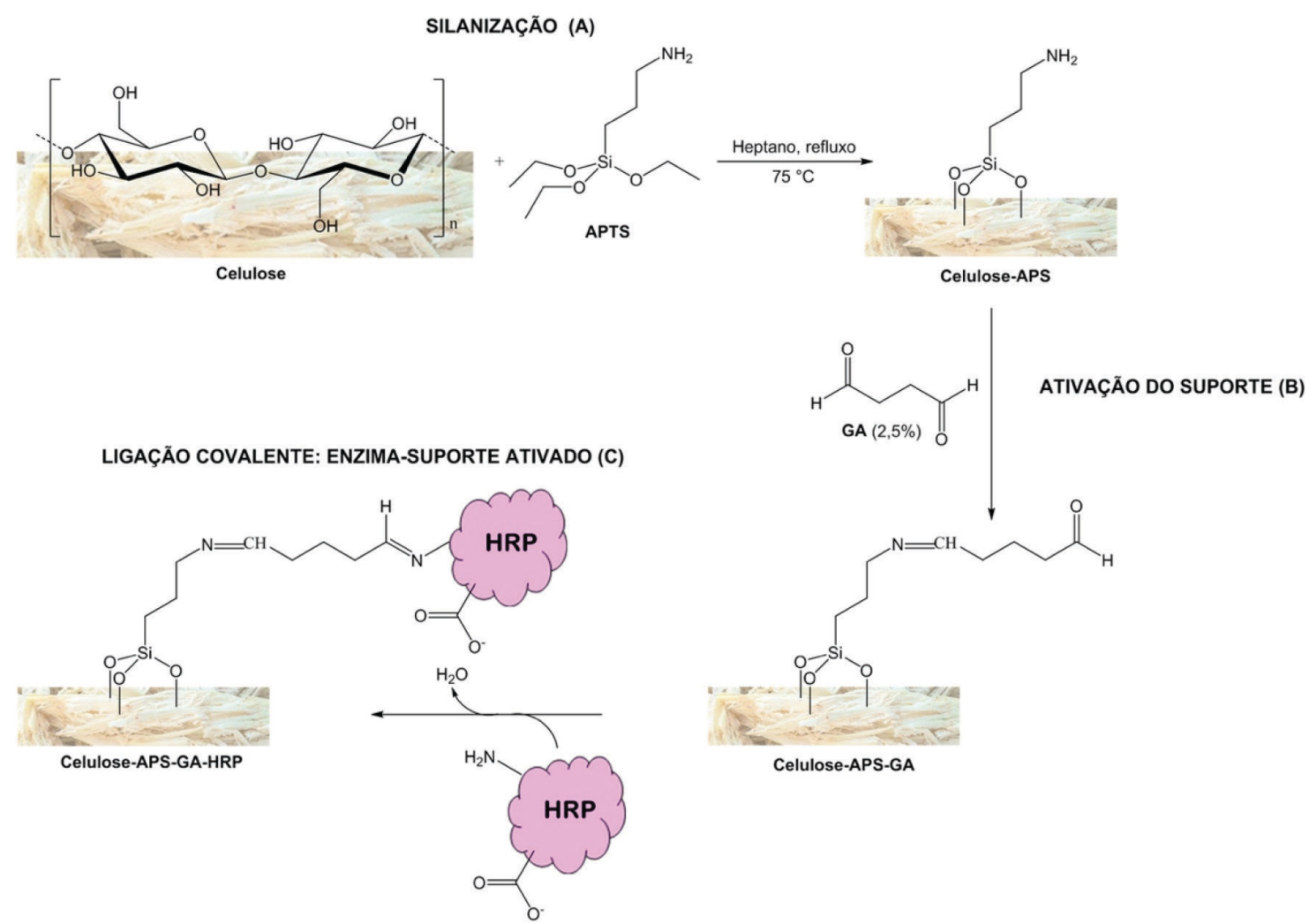

Figura 5. Proposta de imobilização de HRP em bagaço de cana-de-açúcar por ligação covalente. (A) silanização, (B) ativação do suporte com glutaraldeído $2,5 \%(v / v) e(C)$ ligação covalente

Tabela 1. Dados de umidade e perda de massa (\%) de HRP livre, bagaço de cana-de-açúcar (BC) e dos biocatalisadores imobilizados (ADS e LC) por termogravimetria

\begin{tabular}{ccccc}
\hline \multicolumn{5}{c}{ Perda de massa (\%) } \\
\hline Ensaios & $\begin{array}{c}\text { Região I } \\
25-200{ }^{\circ} \mathrm{C}\end{array}$ & $\begin{array}{c}\text { Região II } \\
200-600{ }^{\circ} \mathrm{C}\end{array}$ & $\begin{array}{c}\text { Região III } \\
\text { Acima de } 600{ }^{\circ} \mathrm{C}\end{array}$ & $\begin{array}{c}\text { Umidade } \\
(\%)\end{array}$ \\
\hline HRP Livre & 9,5 & 60,4 & 25,3 & --- \\
BC & 6,9 & 72,7 & 19,7 & 13,39 \\
ADS & 7,9 & 64,3 & 23,6 & 11,75 \\
LC & 8,5 & 65,4 & 22,5 & 24,50 \\
\hline
\end{tabular}

curvas termogravimétricas de materiais lignocelulósicos mostram a degradação térmica da celulose na faixa de 240 a $400{ }^{\circ} \mathrm{C}$, conforme preconiza a literatura. ${ }^{29}$ Os materiais lignocelulósicos que apresentam a hemicelulose mostram a degradação entre 200 a $300{ }^{\circ} \mathrm{C}$ e a lignina entre 280 a $700^{\circ} \mathrm{C} .{ }^{37,38}$ De acordo com a literatura, elevadas temperaturas (região III) quando aplicadas em materiais orgânicos, promove decomposição térmica do material lignocelulósico, formando cinzas constituídas de material inorgânico rico em carbono e minerais. ${ }^{24,25}$

\section{CONCLUSÃO}

O bagaço de cana-de-açúcar pré-tratado pelo método alcalino apresentou potencial para a utilização em novos processos, como por exemplo, suporte orgânico para imobilização de enzimas. A

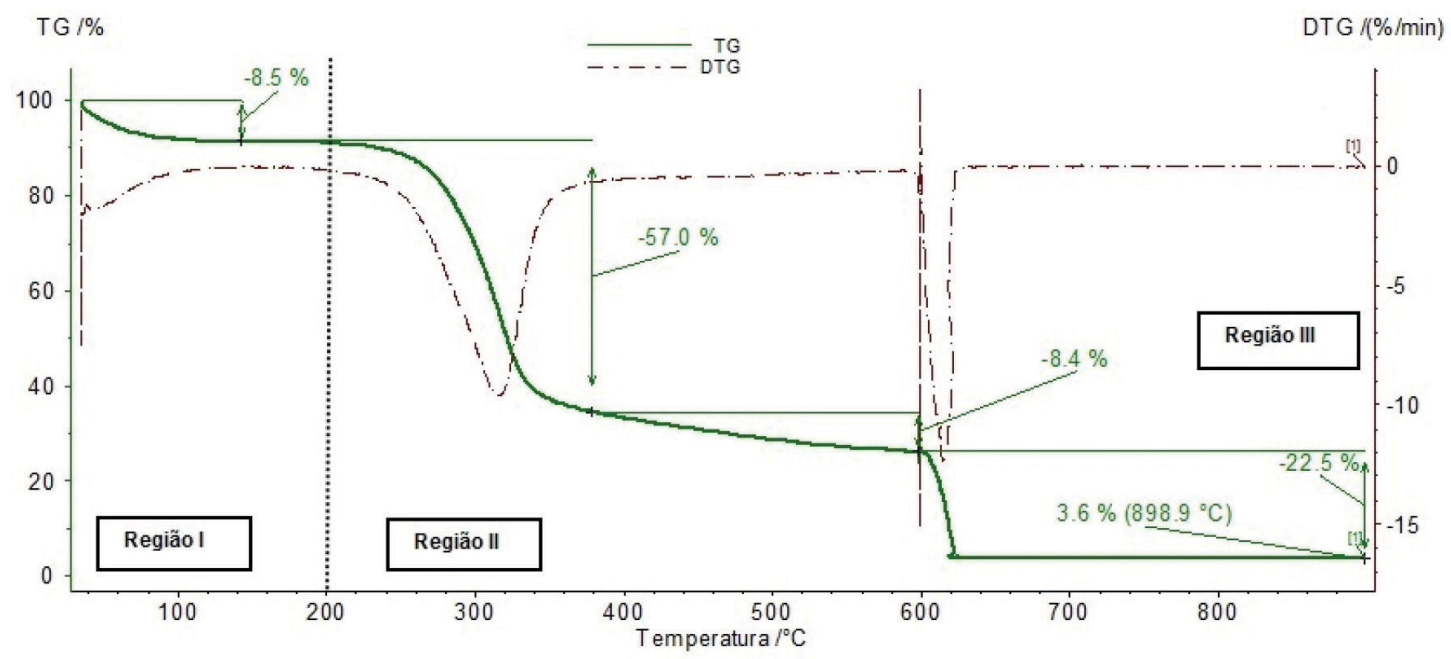

Figura 6. Curva Termogravimétrica de HRP imobilizada por ligação covalente (LC) 
maior eficiência foi observada utilizando $2 \mathrm{mg}$ de HRP/g de suporte para a imobilização por ligação covalente $(35 \%)$. A caracterização por FTIR confirmou a presença de bandas características de HRP e as bandas presentes em materiais lignocelulósicos. Os termogramas confirmaram regiões de degradações de HRP, celulose e a presença de água. A maior perda de massa na região I foi verificada para o derivado imobilizado por $\mathrm{LC}$, confirmando que a presença de água possivelmente favoreceu a atividade de HRP imobilizada no bagaço de cana-de-açúcar.

\section{AGRADECIMENTOS}

Este trabalho foi financiado pelas agências de fomento brasileiras: CAPES, CNPq e FAPITEC/SE.

\section{REFERENCIAS}

1. http://www.factfish.com/statistic-country/brazil/ sugar $\% 20$ cane $\% 2 \mathrm{C} \% 20$ production\%20quantity, acessada em agosto 2018.

2. https://www.conab.gov.br/info-agro/safras/cana.pdf, acessada em agosto 2018.

3. http://www.udop.com.br/index.php?item=noticias \& cod $=1153990$, acessada em agosto 2018 .

4. Barros, J. A. S; Krause, M. C.; Lazzari, E.; Bjerk, T. R.; Amaral, A. L. F.; Camarão, E. B.; Krause, L. C.; $\quad$ Microchem. J. 2018, 137, 30.

5. http://www.oecd.org/sti/biotech/49024032.pdf, acessada em agosto 2018.

6. Aditiya, H. B.; Mahlia, T. M. I.; Chong, W. T.; Nur, H.; Sebayang, A. H.; Renewable Sustainable Energy Rev. 2016, 66, 631.

7. Neto, A. C.; Guimarães, M. J. O. C.; Freire, E.; J. Cleaner Prod. 2018, $184,168$.

8. Amin, H. A.; Secundo, F.; Amer, H.; Mostafa, F. A.; Helmy, W. A.; Biotechnol. Rep. 2018, 17, 55.

9. Santo, M. E.; Rezende, C. A.; Bernardinelli, O. D.; Jr, N. P.; Curvelo, A. A. S.; Azevedo E. R.; Guimarães, F. E. G.; Polikarpov I.; Ind. Crops Prod. 2018, 113, 64.

10. Brígida, A. I. S.; Pinheiro, A. D. T.; Ferreira, A. L. O.; Pinto, G. A. S.; Gonçalves, L. R. B.; Appl. Biochem. Biotechnol. 2007, 136, 67.

11. Mohamed, S.; Darwisha, A.; El-Shishtawy, R.; Process Biochem. 2013, 48, 649

12. Tian, S. Q.; Zhao, R. Y.; Chen, Z. C.; Renewable Sustainable Energy Rev. 2018, 91, 483 .

13. Anwar, Z.; Gulfraz, M.; Irshad, M.; J. Radiat. Res. Appl. Sci. 2014, 7, 163.

14. Kurian, K. J.; Nair, R. G.; Hussain, A.; Raghavan, G. S. V.; Renewable Sustainable Energy Rev. 2013, 25, 205.
15. Hooda, V.; Archita; Food Chem. 2018, 239, 1100.

16. Bilial, M.; Rasheed, T.; Iqbal, H. M. N.; Hu, H.; Wang, W.; Zhang, X.; Int. J. Biol. Macromol. 2018, 113, 983.

17. Wang, Q.; Xue, R.; Guo, H.; Wei, Y.; Yang, W.; J. Electroanal. Chem. 2018, 817,184

18. Santos, D. T.; Sarrouh, B. F.; Rivaldi, J. D.; Converti, A.; Silva, S. S.; J. Food Eng. 2008, 86, 542.

19. Chouyyok, W.; Panpranot, J.; Thanachayanant, C.; Prichanont, S.; J. Mol. Catal. B: Enzym. 2009, 56, 246.

20. Hirata, T.; Izumi, S.; Ogura, M.; Yawata, T.; Tetrahedron 1998, 54, 15993.

21. Cristóvão, R. O.; Tavares, A.; Brigida, A.; Loureiro, J.; Rui, A. R.; J. Mol. Catal. B: Enzym. 2011, 72, 6.

22. Hu, Z.; Xu, L.; Wen, X.; J. Environ. Sci. 2012, 25, 181.

23. Carlsson, N.; Gustafsson, H.; Thörn, C.; Olsson, L.; Holmberg, K.; Åkerman, B.; Adv. Colloid Interface Sci. 2014, 205, 339.

24. Edreis, E. M. A.; Luo, G.; Yao, H.; J. Anal. Appl. Pyrolysis 2014, 107, 107.

25. Wu, H.; Zhao, Y.; Long, Y.; Zhu, Y.; Wang, H.; Lu, W.; Bioresour. Technol. 2011, 102, 9403.

26. Park, B.; Ko, K.; Yoon, D.; Kim, D.; Enzyme Microb. Technol. 2012, 51, 81.

27. Cao, X.; Yu, J.; Zhang, Z.; Liu, S.; Biosens. Bioelectron. 2012, 35, 101.

28. Cao, S.; Aita, G. M.; Bioresour. Technol. 2013, 131, 357.

29. Chen, W.; Ye, S.; Sheen, H.; Appl. Energy 2012, 93, 237.

30. Moretti, M. M. S.; Bocchini-Martins, D. A.; Nunes, C. C. C.; Villena, M. A.; Perrone, O. M.; Silva, R.; Boscolo, M.; Gomes, E.; Appl. Energy 2014, 122, 189.

31. Mendes, A. A.; Castro, H. F.; Andrade, G. S. S.; Tardioli, P. W.; Giordano, R. L. C.; React. Funct. Polym. 2013, 73, 160.

32. Fernández, M.; Sanromán, M. A; Moldes, D.; Biotechnol. Adv. 2013, 31 , 1808.

33. Singh, R.; Manish K.; Singh, R.; Jung-Kul, L.; Int. J. Mol. Sci. 2013, 14, 1232.

34. Kim, H. J.; Suma, Y.; Lee, S. H.; Kim, J.; Kim, H. S.; J. Mol. Catal. B: Enzym. 2012, 83, 8.

35. Souza, R. S. L.; Faria, E. L.; Figueiredo, R. T; Freitas, L. S.; Iglesias, M.; Mattedi, S.; Zanin, G. M.; Santos, O. A. A.; Coutinho, J. A. P; Lima, A. S.; Soares, C. M. F.; Enzyme Microb. Technol. 2013, 52, 141.

36. Mallamace, C. C.; Mallamace, D.; Vasi, S.; Vasi, C.; Dugo, G.; Comput. Struct. Biotechnol. J. 2015, 13, 33.

37. González, M. E.; Cea, M.; Sangaletti, N.; González, A.; Toro, C.; Diez, M. C.; Moreno, N.; Querol, X.; Navia, R.; J. Biobased Mater. Bioenergy 2013, 7, 724 .

38. Kim, K. H.; Kim, J.; Cho, T.; Choi, J. W.; Bioresour. Technol. 2012, 118 , 158. 